Anaesthesist 2022 - 71:38-49 https://doi.org/10.1007/s00101-021-01018-2 Eingegangen: 29. Januar 2021 Überarbeitet: 21. Juni 2021

Angenommen: 23. Juni 2021

Online publiziert: 24. August 2021

(C) Springer Medizin Verlag $\mathrm{GmbH}$, ein Teil von Springer Nature 2021

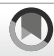

Check for
updates

\section{Seltene Superinfektion bei einem COVID-19-Patienten - Eine Chronologie}

\author{
E. Gamon · D. Tammena - M. Wattenberg · T. Augenstein \\ Klinik für Anästhesiologie, Intensivmedizin und Notfallmedizin, Klinikum Links der Weser, Bremen, \\ Deutschland
}

\title{
Zusammenfassung
}

Bei einem 55-jährigen Mann, der sich zur elektiven Ablation bei Vorhofflimmern in der Klinik befand, wurde nach einer Reanimationssituation auf der peripheren Station ein SARS-CoV-2-Abstrich positiv getestet. Anamnestisch gab es im Vorwege gesicherten Kontakt zu einem COVID-19-positiven Patienten. Im Verlauf entwickelte sich das Vollbild einer COVID-19-Pneumonie mit umfangreicher intensivmedizinischer Behandlung. Nach rund 2-wöchiger Therapie musste das Weaning bei erneuter Verschlechterung abgebrochen werden, und es ergaben sich bei dem wiederholt hochseptischen Patienten mikrobiologische Nachweise einer Superinfektion mit Cryptococcus neoformans und später Leclercia adecarboxylata. Der Patient wurde erfolgreich behandelt und überlebte die Erkrankung.

Schlüsselwörter

Leclercia adecarboxylata $\cdot$ Cryptokokkus neoformans · Sepsis · ARDS · SARS-CoV-2

\section{Präambel}

Ein 55-jähriger Mann wurde während der ersten Welle der Coronapandemie 2020 in Deutschland nach einer innerklinischen Reanimationssituation bei Asystolie von der peripheren kardiologischen Station intubiert und beatmet auf die Intensivstation verlegt.

Der Herz-Kreislauf-Stillstand erfolgte bei dem Verdacht einer hypoxischen Genese, und ein Wiedererlangen des Kreislaufs ("return of spontaneous circulation“, ROSC) konnte durch das Reanimationsteam nach 4 min erreicht werden. Trotz gesicherten Kontakts zu einer COVID-19positiven Person galt der Patient zum Zeitpunkt der Reanimation, aufgrund eines 6 Tage zuvor abgenommenen SARS-CoV2-PCR-Abstrichs als COVID-19-negativ.

Der Grund der ursprünglichen Aufnahme in die Klinik waren rezidivierende Tachyarrhythmie-Episoden bei bekanntem Vorhofflimmern, die bislang nicht dauerhaft kardiovertiert werden konnten und nun eine Woche vor dem Reanimationsereignis über die elektrophysiologische Abteilung abladiert werden sollten.
Bei Verdacht auf eine ambulant erworbene Pneumonie ("community-acquired pneumonia“, (AP) war im peristationären Verlauf bereits eine Antibiotikatherapie mit Ampicillin \& Sulbactam und Clarithromycin angesetzt worden. Da sich die Entzündungssituation trotz dieser Antibiotikatherapie in den Folgetagen weiter aggravierte, war durch die kardiologischen Kollegen zwei Tage vor dem Reanimationsereignis eine Eskalation auf Meropenem erfolgt, mutmaßlich, um ein größeres Spektrum an Erregern abzudecken.

\section{Aufnahmebefund}

Bei der Aufnahme auf die Intensivstation zeigte sich der intubierte und beatmete $\mathrm{Pa}$ tient hämodynamisch instabil und benötigte moderate Katecholamindosierungen (Noradrenalin $0,26 \mu \mathrm{g} / \mathrm{kgKG} / \mathrm{min}$ sowie Dobutamin $3 \mu \mathrm{g} / \mathrm{kgKG} / \mathrm{min}$ ), um ein ausreichendes Herzzeitvolumen $(\mathrm{HI}>2,5 \mathrm{l} / \mathrm{min} /$ $\mathrm{m}^{2}$ ) und einen ausreichenden Mitteldruck (MAP > $65 \mathrm{~mm} \mathrm{Hg}$ ) zu erreichen.

$\mathrm{Zu}$ diesem Zeitpunkt ging man von einem septischen Schock auf dem Bo- 


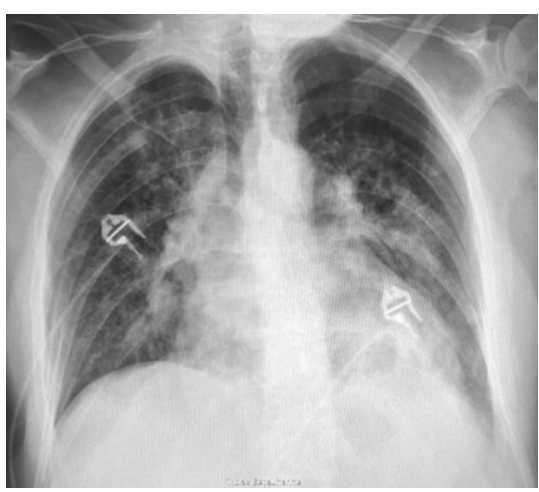

Abb. 1 \ Thoraxröntgenaufnahme am Tag -7, vermutete CAP

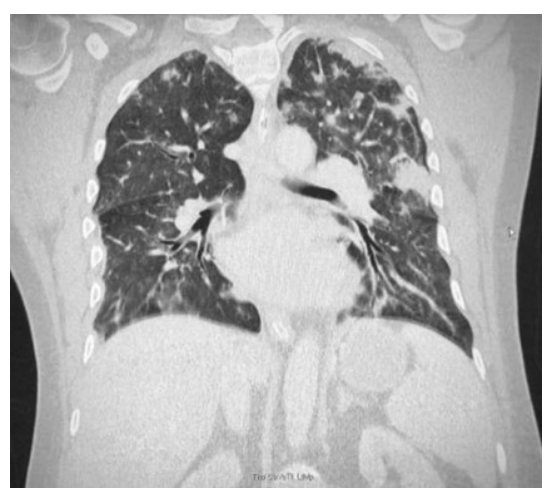

Abb. $4 \Delta$ Thorax-CT-Aufnahme im Verlauf der Therapie auf der Intensivstation am Tag 0. Befund zum Thorax-CT: [...] in allen Lappen/ Segmenten diffus verteilte, teils peribronchiale Verdichtungen, welche zu entzündlichen Parenchymveränderungen passen. Gröbere flächenhafte Konsolidierungen fallen nicht auf. [...]

den der ambulant erworbenen Pneumonie aus, die zusammen mit dem hochgradig eingeschränkten Gaswechsel zur Hypoxie und schließlich zum Herz-KreislaufStillstand geführt hat.

Die mikrobiologische Diagnostik wurde umgehend erweitert und eine Postreanimationsbehandlung eingeleitet, bei der der Patient nach Protokoll mittels Feedback-gesteuerter Oberflächenkühlung (ArcticSun ${ }^{\circledR}$ 5000, Medivance Inc. by BARD Medical Devision Inc., Louisville, CO, USA) auf $33,0^{\circ} \mathrm{C}$ für $24 \mathrm{~h}$ heruntergekühlt wurde. Ein Thermoblasenkatheter bestimmte die notwendige Temperatur zur Steuerung der Oberflächenkühlung.

Die Sedierung wurde zu diesem Zeitpunkt mit Sufentanil und Midazolam geführt und während der Hypothermie mit einer Sedierungstiefe von -5 nach der Rich-

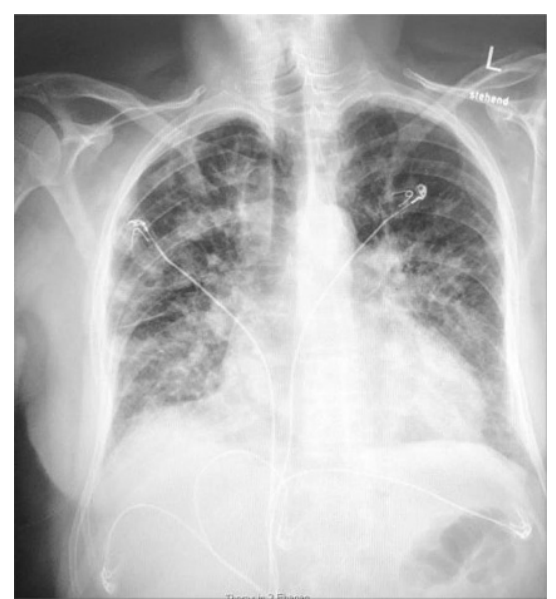

Abb. 2 ム Thoraxröntgenaufnahme am Tag -1, deutliche Progredienz

mond Agitation Sedation Scale (RASS) angestrebt.

Nach Sichtung der kompletten Vorbefunde des Patienten, dem aktuellen klinischen Eindruck und neuen radiologischen und laborchemischen Befunden wurde direkt nach der Aufnahme bei einer Bronchoskopie ein erneuter SARS-CoV-2-PCR-Test abgenommen. Der Patient war zu diesem Zeitpunkt bereits vorsorglich isoliert. Dieser SARS-CoV-2-Test wurde noch am selben Tag positiv bestätigt. Zum Zeitpunkt des beschriebenen Falls in der ersten Welle der Pandemie wurden durch das zuständige Labor noch keine ct-Werte übermittelt.

Bei der nun aktualisierten Diagnose einer COVID-19-Pneumonie mit konsekutiver Hypoxämie und Asystolie wurde die bis dato laufende Antibiotikatherapie mit Meropenem aus dem peripher-stationären Aufenthalt abgesetzt. Radiologisch erhärtete sich folgend der Verdacht einer begleitenden Aspirationspneumonie, sodass bei dem schwer kranken Patienten eine Antibiose mit Piperacillin/Tazobac und Ciprofloxacin begonnen wurde.

Aufgrund der vorbekannten dilatativen Kardiomyopathie (DCM) war die Hämodynamik stark kompromittiert, und es ließ sich in einem transthorakalen Echo (TTE) lediglich eine Ejektionsfraktion des linken Ventrikels (LVEF) von $25 \%$ messen.

Eine routinemäßig bestimmte NSE zeigte einen Initialwert von $52 \mu \mathrm{g} / \mathrm{l}$.

Die Erkenntnisse zur Behandlung von beatmeten COVID-19-Patienten waren in diesem frühen Stadium der Pandemie

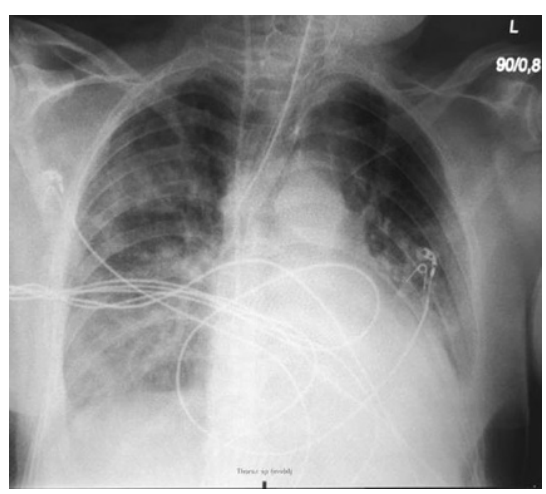

Abb. 3 ॥ Thoraxröntgenbild direkt nach Aufnahme auf die Intensivstation am Tag 0 . Befund zum Thoraxröntgen: [...] Pleuraergüsse, Minderbelüftungen begleitend in den Lungen UF sowie überwiegend fleckförmige Verdichtungen in diffuser Verteilung [...] rechts Führung des Befundes [...]

noch nicht umfangreich, somit erfolgte der primäre Behandlungspfad anhand der gültigen ARDS-Leitlinie [1]. Die Evidenz zur Gabe von Steroiden bei einer COVID19-Infektion war noch sehr gering, daher wurde auf die Gabe von Hydrocortison bei tendenziell fallenden Katecholamindosierungen verzichtet. Die Dexamethasongabe, wie sie heute aus den Daten der RECOVERY-Studie hervorgeht, wurde noch nicht empfohlen [2]. Ebenso war die antivirale Medikation mit Remdesivir ${ }^{\circledR}$ noch nicht in den Behandlungsalgorithmen der COVID-19-Erkrankung verankert. Eine Aufnahme dieser Therapie erfolgte nach erster Studienlage für ein sehr umschriebenes Patientenkollektiv während des Jahres 2020, wurde später wieder verworfen.

Die folgende Chronologie fasst die Ereignisse zusammen, die schließlich zur Superinfektion mit Cryptococcus neoformans und Leclercia adecarboxylata in Bronchialsekretisolaten führten. Der Tag 0 beschreibt dabei den Tag der Reanimation.

\section{Verlauf/Chronologie}

Tag -16

Es erfolgt die elektive stationäre Aufnahme des Patienten zur Ablation bei rezidivierenden Tachyarrhythmie-Episoden bei Vorhofflimmern. Mehrfache Kardioversionen waren bei bekannter DCM bislang frustran. Es wird eine Aufsättigung mit Amiodaron auf eine Kumulativdosis von $7 \mathrm{~g}$ begonnen. 
Tab. 1 Erregerspektrum CAP. (Nach [3])

\begin{tabular}{|l|l|l|}
\hline $\begin{array}{l}\text { Häufige und } \\
\text { mögliche Erre- } \\
\text { ger }\end{array}$ & Seltene Erreger & Keine Erreger \\
\hline $\begin{array}{l}\text { Streptococcus } \\
\text { pneumoniae }\end{array}$ & $\begin{array}{l}\text { Enterobakterien (E. coli, } \\
\text { K. pneumoniae, P. mirabilis) }\end{array}$ & Vergrünend wachsende Streptokokken \\
\hline $\begin{array}{l}\text { Haemophilus } \\
\text { influenzae }\end{array}$ & Pseudomonas aeruginosa & $\begin{array}{l}\text { Staphylococcus epidermidis und andere } \\
\text { Koagulase-negative Staphylokokken }\end{array}$ \\
\cline { 1 - 1 } $\begin{array}{l}\text { Staphylococcus } \\
\text { aureus }\end{array}$ & & Enterokokken \\
\cline { 3 - 3 } & & $\begin{array}{l}\text { Corynebakterien } \\
\text { Neisserien (außer (sehr selten) N. menin- } \\
\text { gitidis) }\end{array}$ \\
& $\begin{array}{l}\text { Haemophilus-Spezies (außer H. influen- } \\
\text { zae) }\end{array}$ \\
& & Candida-Spezies \\
\hline
\end{tabular}

Zu diesem Zeitpunkt der Coronapandemie werden bei der Aufnahme von Patienten in die Klinik noch keine Routinetestungen auf SARS-CoV-2 durchgeführt. Da der Patient nicht symptomatisch ist, wird keine Notwendigkeit für einen solchen Test gesehen.

\section{Tag -7}

Bei progredienter Dyspnoe erfolgt ein radiologischer Nachweis von linksführenden Infiltraten (• Abb. 1). Es erhärtet sich der Verdacht auf eine Pneumonie und eine Antibiotikatherapie mit Ampicillin \& Sulbactam und Clarithromycin wird unmittelbar begonnen. Da diese Symptomatik nun durch eine erneute Anamnese seit Klinikaufnahme bestehen soll, wird von einer CAP ausgegangen und diese kalkulierte Antibiose nach der aktuellen Leitlinie für ambulante Pneumonien gewählt [3; - Tab. 1]. Ebenso wird zu diesem Zeitpunkt in Erfahrung gebracht, dass es vor der Klinikaufnahme gesicherten Kontakt mit einem COVID-19-positiven Patienten gab. Es erfolgt ein SARS-CoV-2-PCR-Test, der als Mund-Rachen-Nasen-Abstrich abgenommen wird. Dieser Test ist negativ.

\section{Tag -1}

Bei weiterhin deutlicher Einschränkung des Gaswechsels und weiterhin progredienter Dyspnoe des Patienten fallen in einem erneuten Röntgenbild nun fleckige Infiltrate beidseitig auf ( $\mathbf{A b b}$. 2). Zu diesem Zeitpunkt findet lediglich eine Sauerstoffinsufflation auf der peripheren Station statt und keine druckunterstützte
Beatmungsform oder High-Flow-Atemtherapie.

Die Kollegen der zu diesem Zeitpunkt betreuenden Station eskalieren die Antibiotikatherapie auf Meropenem. Warum diese Eskalationsstufe gewählt wird, bleibt unklar. Mutmaßlich soll das Erregerspektrum des Antibiotikums maximal erweitert werden. Ein mikrobiologischer Befund liegt zu diesem Zeitpunkt nicht vor.

\section{$\operatorname{Tag} 0$}

Im Patientenzimmer kommt es zum HerzKreislauf-Stillstand, am ehesten bei einer hypoxischen Genese im Sinne der vorbestehenden Pneumonie. Ein ROSC wird nach 4 min erreicht und der Patient beatmet auf die Intensivstation gebracht.

Die Beatmungssituation zeigt sich direkt nach der Intubation mit hohen Beatmungsdrücken und hohen Sauerstofffraktionen schwerwiegend beeinträchtigt $\left(\mathrm{F}_{1} \mathrm{O}_{2}\right.$ 0,8/PEEP $10 \mathrm{mmHg} /{ }_{\text {"Idiving }}$ pressure" $15 \mathrm{mmHg} /$ Oxygenierungsindex 227).

Eine transthorakale Echokardiographie zeigt keine wesentliche Änderung zu den vorherigen Befunden im Sinne von neuen regionalen Wandbewegungsstörungen oder Klappenvitien. Auf eine Herzkatheteruntersuchung wird aufgrund fehlender Enzymkinetik (Troponin, CK-MB) und fehlenderEKG-Veränderungen vorerst verzichtet.

Der Patient wird im Rahmen des Postreanimationsschemas mit einer therapeutischen Hypothermie (TTM) behandelt und auf $33^{\circ} \mathrm{C}$ heruntergekühlt.

Ein erneuter SARS-CoV-2-Test aus dem Sekret einer Bronchoskopie fällt positiv
Infobox 1

Erregerspektrum der HAP. (Nach [4])

- Enterobacteriaceae

- E. coli

- Klebsiella-Spezies

- Enterobacter-Spezies

- Haemophilus influenzae

- Staphylococcus aureus (MSSA)

- Streptococcus pneumoniae

- Zusätzlich:

- Methicillin-resistente Staphylococcus aureus (MRSA)

- ESBL-bildende Enterobakterien

- Pseudomonas aeruginosa

- Acinetobacter baumannii

- Stenotrophomonas maltophilia

aus. Die auf der peripheren Station begonnene kalkulierte Antibiotikatherapie mit Meropenem bei einer unklaren Infektsituation wird nach einer nur einmaligen Gabe des Meropenem bei dem nun hochgradigen Verdacht einer nichtsuperinfizierten COVID-19-Pneumonie abgesetzt.

Radiologisch und bronchoskopisch erhärtet sich jedoch im Verlauf der Diagnostik der Verdacht einer stattgefundenen Aspiration unter der Reanimation, weshalb eine Kombinationsantibiotikatherapie mit Piperacillin/Tazobactam und Ciprofloxacin begonnen wird (- Abb. 3 und 4). Die Wahl der antibiotischen Therapie ist neben dem Verdacht der Aspiration durch die zu diesem Zeitpunkt lange Hospitalisierungsdauer von über 14 Tagen bedingt. Darüber hinaus ist ein Vorhandensein eines erweiterten Erregerspektrums mit Veränderungen im gramnegativen Keimspektrum möglich, ebenso wie die vorherige lange Behandlung mit Ampicillin \& Sulbactam.

Hier wird entsprechend der Leitlinie zur nosokomialen Pneumonie (,hospitalacquired pneumonia", HAP) gehandelt, dies entspricht in vollem Umfang den hausinternen Leitlinien ([4]; $\mathbf{0}$ Infobox 1).

Die Entzündungswerte sind zu diesem Zeitpunkt moderat mit einem CRP von $149 \mathrm{mg} / \mathrm{l}$ und einem PCT von 0,9 $\mathrm{gg} / \mathrm{l}$.

In den folgenden Tagen lässt sich mikrobiologisch aus dem Bronchialsekret lediglich Enterococcus faecium isolieren. Die Antibiotikatherapie wird - trotz der Enterokokkenresistenz auf das verabreichte Piperacillin/Tazobactam - nicht umgestellt, da Enterokokken keine Pneumonie-Erreger sind und die Befundkonstellation des- 


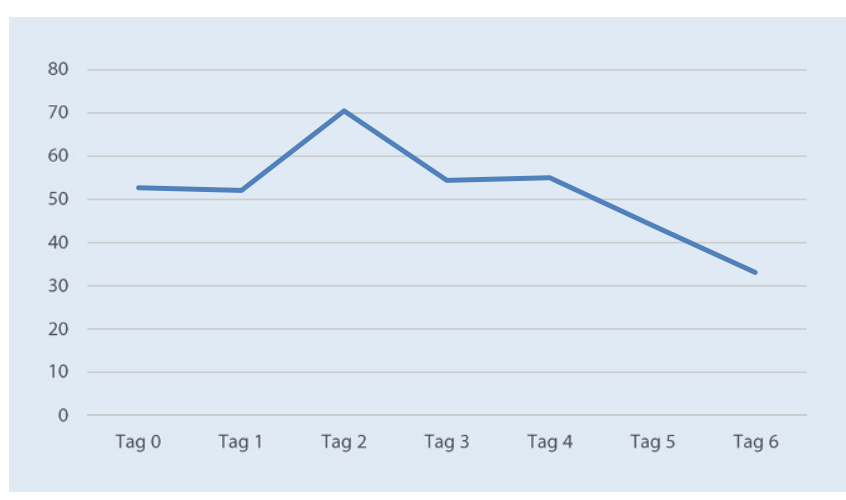

Abb. $5 \triangleleft$ NSE-Verlauf in der ersten Woche nach Reanimation in $\mu \mathrm{g} / \mathrm{l}$
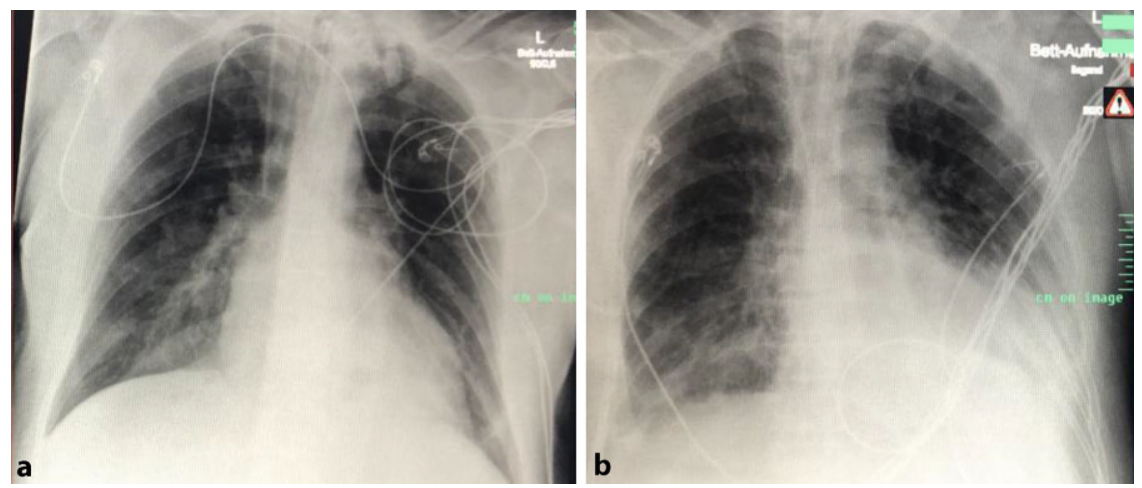

Abb. 6 \ Thoraxröntgenaufnahmen, a Tag 5, b Tag 9. Befund zum Thoraxröntgen, Tag 5 (a): Beidseits infrahiläre Zeichnungsvermehrung des pulmonalen Parenchyms [...] rückläufiger Befund bezüglich der Infiltrationen [...]. Befund zum Thoraxröntgen, Tag 9 (b): Basale Ergüsse in diskreter Ausprägung. Minderbelüftungen rechts infrahilär, DD entzündlich [...]

halb ohne klinische Bedeutung gewertet wird. Zu keiner Zeit wird dieser Erreger in einer Blutkultur nachgewiesen, und es treten im gesamten Verlauf keine Vancomycin-resistenten Stämme (VRE) auf.

Es zeigen sich erwartete Laborwerte hinsichtlich einer COVID-19-Erkrankung verändert, insbesondere D-Dimere $7990 \mu \mathrm{g} / \mathrm{l}$, Neutrophile $9,1 / \mathrm{nl}$ und LDH $1127 \mathrm{U} / \mathrm{l}$.

\section{Tag 1}

Die Situation des Gaswechsels und der globalen pulmonalen Situation zeigt sich unter der Beatmungstherapie gebessert.

\section{$\operatorname{Tag} 2$}

Der Patient erreicht die Normothermie und soll in ein niedrigeres Sedierungslevel (RASS -3 bis -2 ) gebracht werden, um in eine druckunterstützte Beatmung im Sinne von CPAP/ASB überführt zu werden $\left(\mathrm{F}_{1} \mathrm{O}_{2}\right.$ 0,3/PEEP 12/Driving pressure 10$)$.
Die Therapie mit Ciprofloxacin muss bei erhöhten QTc-Zeiten abgesetzt werden. Die elektrophysiologische Abteilung mittlerweile neben der vermuteten hypoxischen Genese eine rhythmogene Ursache (Long-QT) vermutet. Das Piperacillin/ Tazobactam wird aber weitergeführt.

\section{Tag 4}

Bei täglicher Besserung der pulmonalen Situation wird versucht, das Weaning auszudehnen, allerdings bleibt es unter verschiedenen medikamentösen Regimen frustran, sodass der Patient unter strenger Einhaltung aller Schutzmaßnahmen bei bestätigter SARS-CoV-2-Infektion dilatativ tracheotomiert wird. Zu diesem Zeitpunkt wird die Technik des Abdeckens des Patienten mit einer durchsichtigen Kunststofffolie verwendet, um die Aerosolbildung während der Maßnahme zu reduzieren.

Nach der Tracheotomie ist der Gaswechsel bei vermuteten Atelektasen wieder deutlich schlechter, sodass die Ent- scheidung zu einer Vertiefung der Sedierung und einer folgenden 16-stündigen Bauchlage fällt.

\section{$\operatorname{Tag} 10$}

Zu diesem Zeitpunkt kann die Katecholamintherapie beendet werden. Die Weaning-Versuche und Sedierungsreduktion der letzten Tage sind erfolgreich, sodass erste Kontaktaufnahmen mit dem Patienten möglich sind.

\section{Tag 11}

Erste neurologisch adäquate Reaktionen wie Händedrücken und Blickkontakt sind möglich und lassen auf ein gutes neurologisches Outcome schließen. Die NSE-Werte zeigen sich nach einem initialen Wert von $52,7 \mu \mathrm{g} / \mathrm{l}$ am Tag 0 bis zum Tag 6 fallend (- Abb. 5).

Jedoch kommt es im weiteren Tagesverlauf zu einer Verschlechterung des Gaswechsels, begleitet von steigenden Entzündungswerten (CRP $253 \mathrm{mg} / \mathrm{l}$ ) und einem erneuten Katecholaminbedarf. Als Hauptfokus wird ein erneuter pulmonaler Infekt vermutet.

Es erfolgt eine umfangreiche mikrobiologische Diagnostik mit Blutkulturen, Trachealsekret und einer Liquorpunktion, bei auffälliger Neurologie und einer möglichen zerebralen Beteiligung der Virusinfektion. Darüber hinaus werden alle Fremdmaterialien und alle Katheter gewechselt. Sonographisch und radiologisch zeigen sich die Infiltrate erneut zunehmend (『Abb. 6a, b).

Nach Vertiefung der Sedierung wird der Patient erneut auf dem Bauch gelagert. Die antibiotische Therapie wird auf Meropenem und Linezolid bei vermuteter Superinfektion der COVID-19-Pneumonie im Sinne eines Substanzwechsels verändert. Bei Vorbehandlung der initialen Aspirationspneumonie mit Piperacillin/ Tazobactam bis einschließlich zum Vortag (Therapiedauer 10 Tage) und eines nun erneuten inflammatorischen Bildes unter laufender antibiotischer Therapie wird diese Kombination gewählt, um ein größeres Wirkspektrum (MRSA, ESBL-Produzenten und 3-MRGN) zu erreichen. Da 4-MRGN eine Rarität im Klinikum Links der 


$\begin{array}{ll}\begin{array}{l}\text { MIKROBIOLOGIE } \\ \text { 1) Material } \\ \text { Kulturen } \\ \text { aerob }\end{array} & \text { Bronchialsekret } \\ \text { anaerob } & \begin{array}{l}\text { mäßig Cryptococcus neoformans } \\ \text { Keine Keime der normalen Rachenflora } \\ \text { Nach 2-tägiger Bebrütung negativ. Die } \\ \text { Kultur wird insgesamt } 5 \text { Tage bebrütet, } \\ \text { im Fall von späterem Wachstum erfolgt } \\ \text { eine Nachmeldung. }\end{array}\end{array}$

Abb. $7 \Delta$ Mikrobiologischer positiver Nachweis von Cryptococcus neoformans im Bronchialsekret

Weser darstellen, wird das Meropenem als ausreichend erachtet.

Bis auf die bereits bekannten mikrobiologischen Befunde gibt es bis dato keine neuen Erkenntnisse.

$\operatorname{Tag} 13$

Der Patient entwickelt ein septisches Schockgeschehen, gekennzeichnet durch steigende Temperaturen und einen kontinuierlich erhöhten Bedarf an Katecholaminen bis $0,14 \mu \mathrm{g} / \mathrm{kgKG} / \mathrm{min}$ für einen suffizienten Kreislauf.

Die mikrobiologischen Untersuchungen liefern den Nachweis von Cryptococcus neoformans in mehrfachen mikrobiologischen Bronchialsekretproben; die Liquorbefunde sind unauffällig ( $\bullet$ Abb. 7 und 8).

Es wird eine antimykotische Therapie mit Amphotericin B und Flucytosin zusätzlich zum laufenden Meropenem und Linezolid begonnen.

\section{$\operatorname{Tag} 14$}

Während sich der Gesamtzustand unter der Therapie deutlich stabilisiert, wird ein Staphylococcus epidermidis in den meisten Blutkulturen nachgewiesen und somit nicht als Kontamination gewertet. In der antibiotischen Therapie erfolgt als Konsequenz die Umstellung von Linezolid auf Vancomycin, da zu diesem Zeitpunkt noch kein Antibiogramm vorliegt und eine mögliche Resistenzlage (zunehmend Linezolidresistente $S$. epidermidis) berücksichtigt werden muss. Des Weiteren wird die Empfehlung zur Behandlung einer Blutstrominfektion umgesetzt, die eine bakterizide Therapie der antibiotischen Therapie mit dem bakteriostatischen Linezolid vorzieht [5].

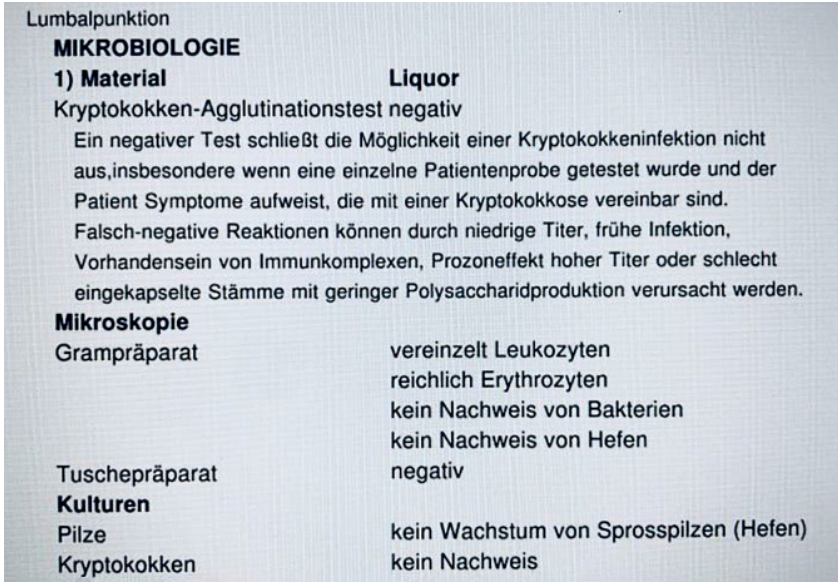

Abb. $8 \Delta$ Mikrobiologischer negativer Nachweis von Cryptococcus neoformans im Liquor

Retrospektiv muss an einen kontaminierten ZVK vor dem Wechsel am Tag 11 gedacht werden, dieser zeigt sich aber in einer mikrobiologischen Untersuchung als steril. Die Bakteriämie mit Staphylococcus epidermidis kann in diesem Stadium des Krankheitsverlaufs und bei dem immunkompromittierten Zustand des Patienten nicht ignoriert werden und damit auch keine abwartende Haltung eingenommen werden. Als Auslöser des septiformen Bildes muss ebenfalls Cryptococcus neoformans in Betracht gezogen werden.

Ein transösophageales Echo zeigt keine Vegetationen auf den Herzklappen, allerdings aber einen bis dato unbekannten intraatrialen Septumdefekt, der nach interdisziplinärer Besprechung mit den Kollegen der Kardiologie und Elektrophysiologie als Folge der erfolgten Pulmonalvenenisolation gewertet wird.

In den darauffolgenden Tagen wird bei zunehmender Besserung erneut mit dem Weaning begonnen. Im Weiteren werden das Vancomycin und schließlich das noch laufende Meropenem abgesetzt.

\section{$\operatorname{Tag} 22$}

Unter der medikamentösen Therapie mit Dexmedetomidin können bei neu aufgetretenen Agitations- und Angstzuständen eine gute Führbarkeit und Kontaktierbarkeit des Patienten erreicht werden. Das Weaning schreitet nach Protokoll voran, und es kommt zu ersten Spontanatmungsphasen.

\section{$\operatorname{Tag} 25$}

Unter dem laufenden Weaning kommt es zu Fieberspitzen bis knapp $40^{\circ} \mathrm{C}$. Nach der Abnahme weiterer Blutkulturen werden alle vorhandenen Katheter gewechselt und eine weitere Antibiotikatherapie kalkuliert mit Meropenem und Linezolid begonnen. Da die letzte Therapie mit diesen Substanzen etwa 11 Tage zurückliegt, wird wiederholt auf das große Wirkspektrum dieser Kombination zurückgegriffen. Umfangreiche diagnostische Untersuchungen (CT, TEE, Sonographie) bleiben ohne neuen pathologischen Befund; lediglich die Infiltrate erscheinen progredient (- Abb. 9).

Es wird die Entscheidung zur CVVHD getroffen, da die Retentionswerte (Kreatinin, Harnstoff) unter der Diuretikatherapie mit Furosemid ansteigen und auch das Kalium $5,9 \mathrm{mmol} / \mathrm{l}$ überschreitet.

Schon am Folgetag kommt es zu einer deutlichen Besserung dieser septischen $\mathrm{Si}$ tuation.

\section{Tag 31}

In weiteren Bronchialsekretproben erfolgt der Nachweis von Leclercia adecarboxylata. Gemäß dem Antibiogramm erfolgt die Deeskalation der laufenden Antibiotikatherapie auf Piperacillin/Tazobac. Auch die dato gegebene antibiotische Therapie war für dieses Resistenzmuster vollumfänglich wirksam (- Abb. 10). 


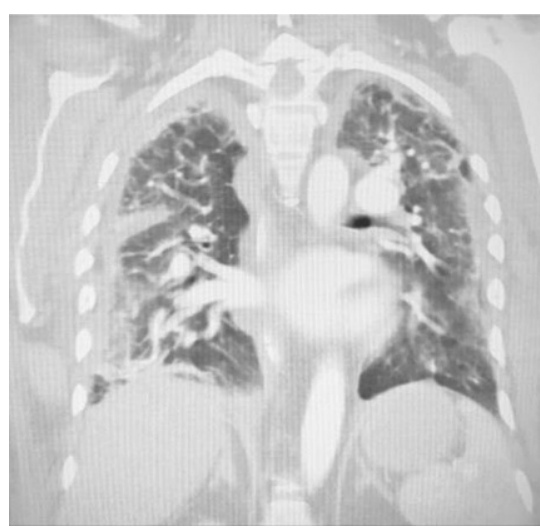

Abb. $9 \Delta$ Thorax-CT-Aufnahme, Tag $25 \mathrm{im}$ Fieberanstieg. Befund zum CT am Tag 25: [...] erscheinen die vorbeschriebenen infiltratsuspekten fleckigen Verdichtungen abschnittsweise progredient, insbesondere im rechten Oberlappen, teilweise auch mit progredienten Milchglasparenchymeintrübungen. Geringe Pleuraergüsse beidseits [...] Begleitende basale Dystelektasen

\section{Tag 34}

Zum weiteren Weaning, der folgenden Dekanülierung und zur späteren Atemtherapie wird der Patient 34 Tage nach der Reanimation auf die Weaning-Station der Lungenfachabteilung der Schwesterklinik verlegt (- Abb. 11 und 12).

\section{Diskussion}

Der dargestellte Fallbericht beschreibt den Verlauf einer COVID-19-Infektion bei einem männlichen, 55-jährigen Patienten mit konsekutiver Intensivbehandlung und Langzeitbeatmung.

Während ein initial abgenommener SARS-CoV-2-PCR-Test negativ war und daher von einer CAP ausgegangen wurde, ist ein zweiter Test 7 Tage später nach einem hypoxisch bedingten Reanimationsereignis positiv. Im Kontext der Reanimation wurde zusätzlich zur Hypoxie ein Long-QT-Syndrom diskutiert, weshalb eine laufende Antibiose mit Ciprofloxacin beendet werden muss. Chinolone haben das Potenzial einer QT-Zeit-Veränderung oder der Aggravation einer bestehenden Herzrhythmusstörung. Es muss allerdings zwingend auch die bis zu diesem Zeitpunkt laufende Aufsättigung mit Amiodaron in Betracht gezogen werden. Auch dieses Medikament kann QT-Zeit-Veränderun-

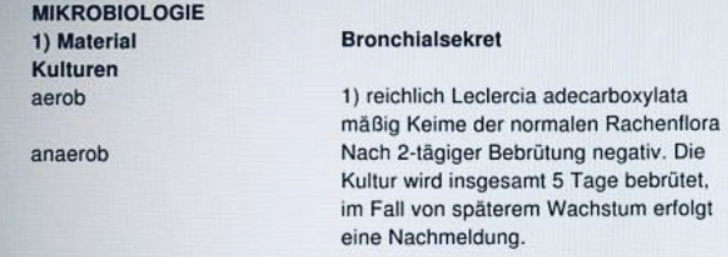

Bemerkung:

3: Resultate automatisch am 02.05.20 um 12:48 getaxt

Resultate automatisch am 04.05.20 um 17:02 gefaxt

Befund wurde medizinisch validiert. Rūckfragen unter: Dr. Sandkamp

\begin{tabular}{|l|r|}
\hline Antibiogramm & 1 \\
\hline & S \\
\hline Ampicillin & S \\
\hline Ampicillin+Sulbactam & $\mathrm{S}$ \\
\hline Piperacillin & $\mathrm{S}$ \\
\hline Piperacillin+Tazo. & $\mathrm{S}$ \\
\hline Cefpodoxim & $\mathrm{S}$ \\
\hline Cefuroxim & $\mathrm{S}$ \\
\hline Cefuroxim-Axetil & $\mathrm{S}$ \\
\hline Cefixim & $\mathrm{S}$ \\
\hline Cefotaxim & $\mathrm{S}$ \\
\hline Ceftazidim & $\mathrm{S}$ \\
\hline Cotrimoxazol & $\mathrm{S}$ \\
\hline Ofloxacin & $\mathrm{S}$ \\
\hline Ciprofloxacin & $\mathrm{S}$ \\
\hline Gentamicin & $\mathrm{S}$ \\
\hline Imipenem & $\mathrm{S}$ \\
\hline Meropenem &
\end{tabular}

Abb. 10 А Mikrobiologischer positiver Nachweis Leclercia adecarboxylata im Bronchialsekret

gen bewirken [6]. Die genaue Ursache des Herz-Kreislauf-Stillstands blieb unklar.

Diese Fallschilderung passt in der zeitlichen Abfolge zur heutigen Erkenntnis des Verlaufs einer COVID-19-Infektion. Die klinische Verschlechterung nach anfänglich leichten Symptomen tratetwa 8 bis 15 Tage nach der Virusexposition und damit dem Krankheitsbeginn auf [7].

Der Gesamtverlauf einer COVID-19Erkrankung wird durch das Modell der drei Krankheitsphasen beschrieben. In der ersten Phase, in der eine initiale Virusreplikation stattfindet, imponieren meist nur leichte Krankheitssymptome, und diese Phase endet mit einem leichten Abklingen der Krankheitssymptome. In der zweiten Phase zeigt sich die fulminante septisch-pulmonale Exazerbation, in der hohes Fieber und eine Hypoxämie dominieren und kann schließlich in der dritten Phase münden, als Vollausprägung der Hyperinflammation im Bild eines „acute respiratory distress syndrome" (ARDS; - Abb. 13, [8]).

Bei $20-25 \%$ der Patienten kommt es zu einem schweren Verlauf; etwa 6-7\% der Patienten entwickeln ein ARDS [9].

Während der Intensivtherapie des beschriebenen Patienten kam es zusätzlich zur COVID-19-Pneumonie zu weiteren rezidivierenden pulmonalen Infektionen. Es ließen sich, nach unterschiedlichen kalkulierten Antibiotikatherapien - zwei seltene opportunistische Keime - Leclercia adecarboxylata und Cryptococcus neoformans, nachweisen und schließlich suffizient behandeln.

\section{Exkurs Leclercia adecarboxylata}

Leclercia adecarboxylata ist ein gramnegatives, fakultativ anaerobes Bakterium, das zu der Familie der Enterobakterien gehört und zuerst 1962 von Leclerc beschrieben worden ist ([10]; - Abb. 14). Es kommt ubiquitär in der Natur vor und wurde u.a. aus Nahrungsmitteln und Wasser isoliert. Darüber hinaus gehört es zur Darmflora. In der Regel bestehen keine ausgeprägten Antibiotikaresistenzen, wobei auch schon resistente Stämme beschrieben worden sind [11].

Infektionen mit Leclercia adecarboxylata treten in den meisten Fällen bei immunsupprimierten Patienten auf, jedoch ließ sich das Bakterium in der Vergangenheit auch bei polymikrobiellen Infektionen immunkompetenter Patienten nachweisen.

Fallberichte über Monoinfektionen bei immunkompetenten Patienten gibt es ebenfalls [12, 13]. Merza et al. beschrieben 2019 den Fall einer 51-jährigen Patientin im septischen Schock aufgrund einer Cholezystitis. Aus der Gallenflüssigkeit ließ sich Leclercia adecarboxylata isolieren. Ein Immundefizit war bei dieser Patientin hingegen nicht nachweisbar. Sie verstarb [14].

Im Jahr 2013 veröffentlichten Eiland et al. einen Fall einer 55-jährigen Patientin mit einer Pneumonie durch Leclercia adecarboxylata, die ebenfalls einen schweren Verlauf hatte, aber kein nachweisliches Immundefizit [15]. In einem Fallbericht von Prakash et al. 2015 wurden 3 Fälle mit einer Pneumonie durch Leclercia adecarboxylata beschrieben. Ein Patient litt an 


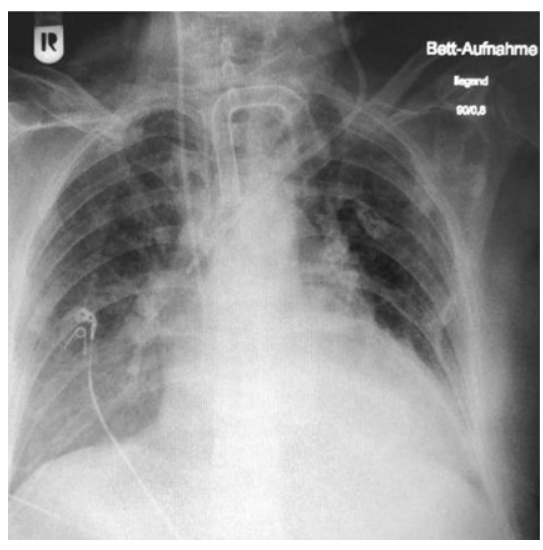

Abb. 11 \ Thoraxröntgenaufnahme bei Verlegung auf die Weaning-Station an Tag 34. Befund zum Thoraxröntgen am Tag 34: [...] Minderbelüftungen beidseits peri-/infrahilär als Ausdruck möglicher Restinfiltrate. Keine neu aufgetretenen entzündlichen Parenchymveränderung, soweit hier bewertbar. [...]

einem Immundefizit, die anderen beiden nicht [16]. Auch in 2 dargestellten Fällen von Mokkapati 2014 zeigen sich lokale Infektionsherde (vaginal und gluteal) mit systemischer Entzündung, die primär von einer Infektion mit Leclercia adecarboxylata ausgingen, und bei denen die Patienten nicht immunkompromittiert waren [17]. In einem weiteren "case report" von Keren 2014 wurde von einem 46-jährigen Mann berichtet, der sich durch eine Verletzung beim Surfen im Mittelmeer mit Leclercia adecarboxylata infizierte, eine lokale Entzündung ausbildete, anamnestisch allerdings völlig gesund war [18].

\section{Exkurs Cryptococcus neoformans}

Cryptococcus neoformans ist ein bekapselter Sprosspilz, welcher weltweit hauptsächlich in Vogelfäkalien vorkommt (- Abb. 15). Er löst bei immunsupprimierten Patienten Infektionen der Atemwege und des Zentralnervensystems aus; Infektionen immunkompetenter Patienten sind selten. Die Inkubationszeit beträgt vermutlich Monate. In der Regel verlaufen Infektionen mit Cryptococcus neoformans bei immunkompetenten Menschen milde bzw. subklinisch, sodass eine Therapie nicht erforderlich ist bzw. die Erkrankung aufgrund der fehlenden Schwere gar nicht erst diagnostiziert wird. Fälle von schweren Verläufen sind allerdings auch für immunkompetente Patienten

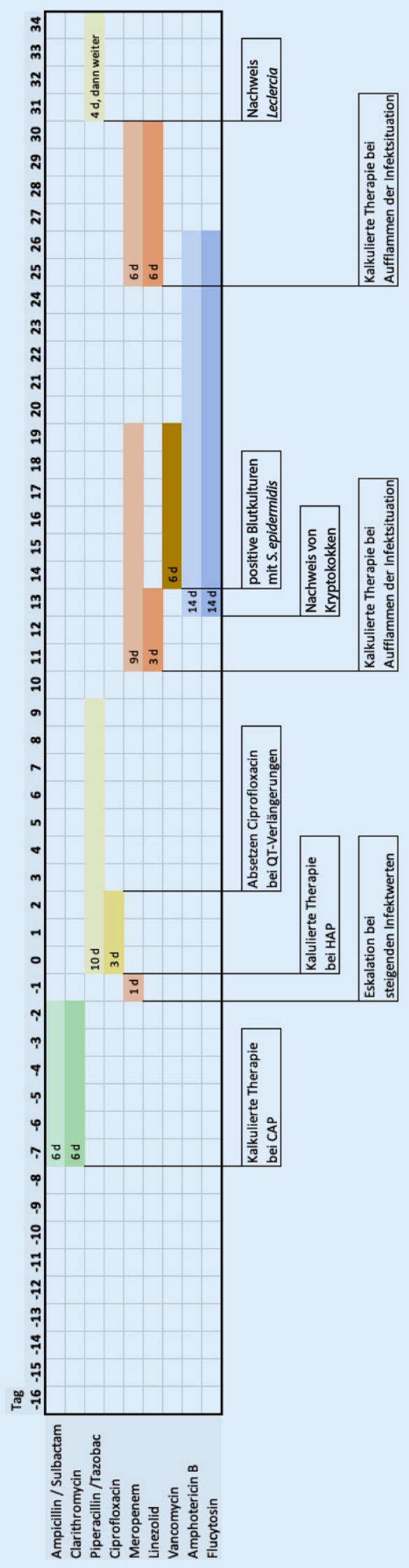

Abb. $12 \triangleleft$ Tabellarischer Verlauf der Antibiotikatherapie 


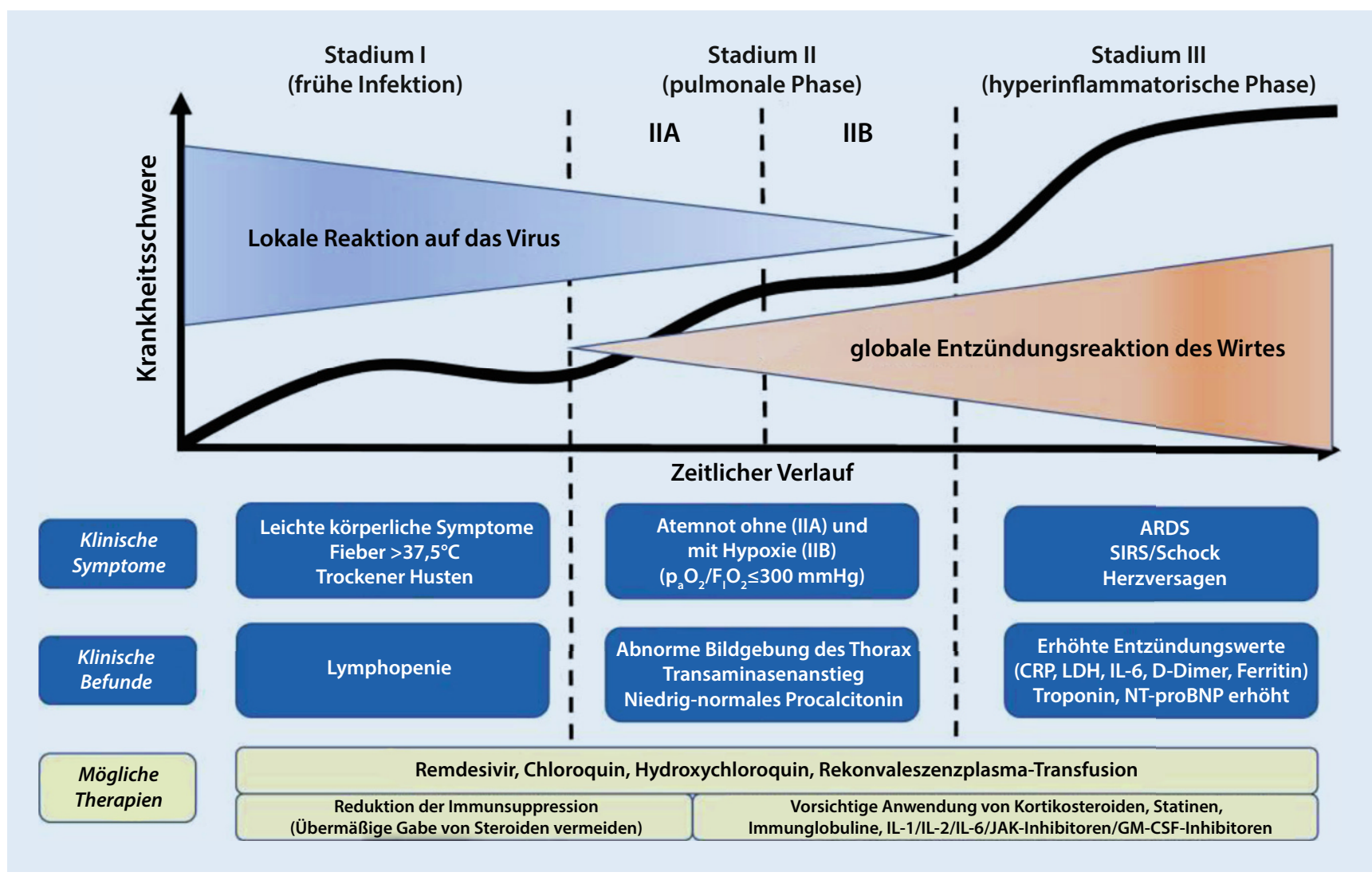

Abb. $13 \Delta$ Klinischer Verlauf einer COVID-19-Erkrankung. (Aus Siddiqi und Mehra [8], mit freundlicher Genehmigung)

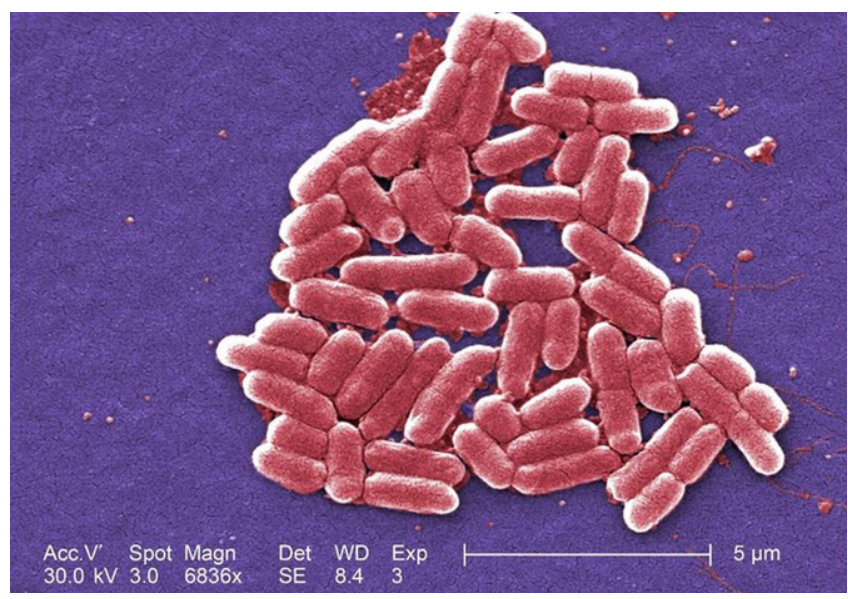

Abb. $14 \Delta$ E. coli als bekanntester Vertreter der Enterobacteriaceae, zu denen auch Leclercia adecarboxylata gehört; ",magnification“: 6,836x. Scanning electron micrograph (SEM). (Author. Janice Haney Carr, Quelle Wikimedia Commons, public domain [46])

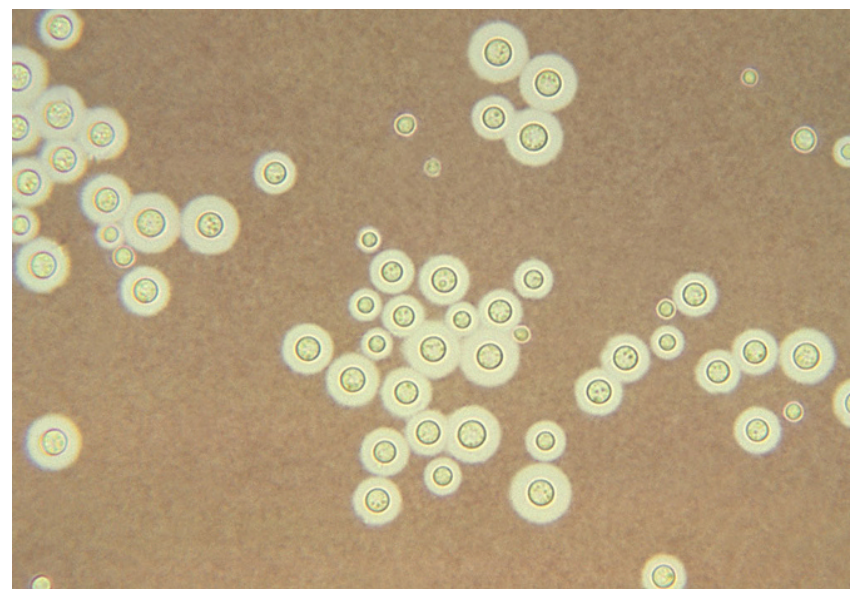

Abb. $15 \Delta$ Cryptococcus neoformans; ,light India ink staining preparation". (Content Providers(s): CDC/Dr. Leanor Haley - Dieses Medium stammt aus der Public Health Image Library (PHIL), mit der Identifikationsnummer \#3771 der Centers for Disease Control and Prevention) beschrieben, insbesondere das Auftreten von Meningitiden [19]. Die Kryptokokkose zählt zu den AIDS-definierenden Erkrankungen [20]. Die Diagnose erfolgt als mikroskopischer Direktnachweis bzw. mittels Antigentest. Die Therapie erfolgt primär mit Amphotericin B (0,7-1 mg/
kgKG und Tag) und Flucytosin (100 mg/ kgKG und Tag) für einen Zeitraum von zunächst 4 Wochen [21].

Beide opportunistischen Erreger, Leclercia adecarboxylata und Cryptococcus neoformans, hatten im beschriebenen Fall zu einer Pneumonie geführt. Dies war radiologisch durch Infiltrate und eine entsprechende Kinetik der Inflammationswerte nachvollziehbar. Zum Zeitpunkt der Infektion bestand eine Lymphopenie

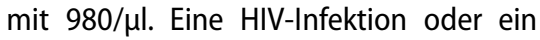
angeborenes Immundefizit lagen nicht vor. 


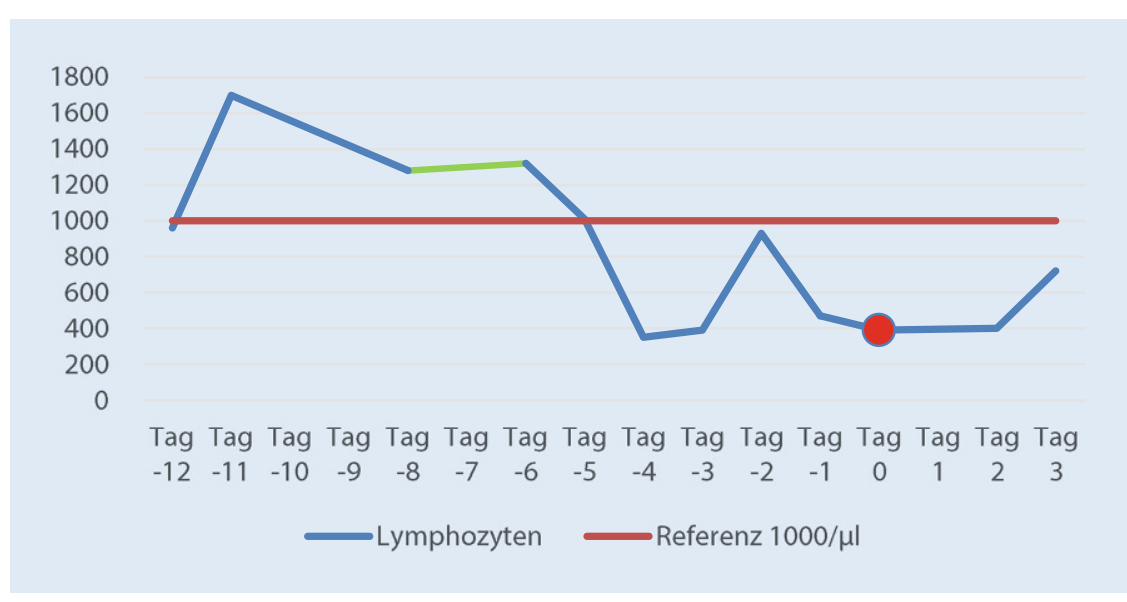

Abb. $16 \Delta$ Lymphozytenzahlverlauf von der stationären Aufnahme bis zur Reanimation (roter Punkt), grün markiert ist der Zeitpunkt um den ersten negativen Coronatest

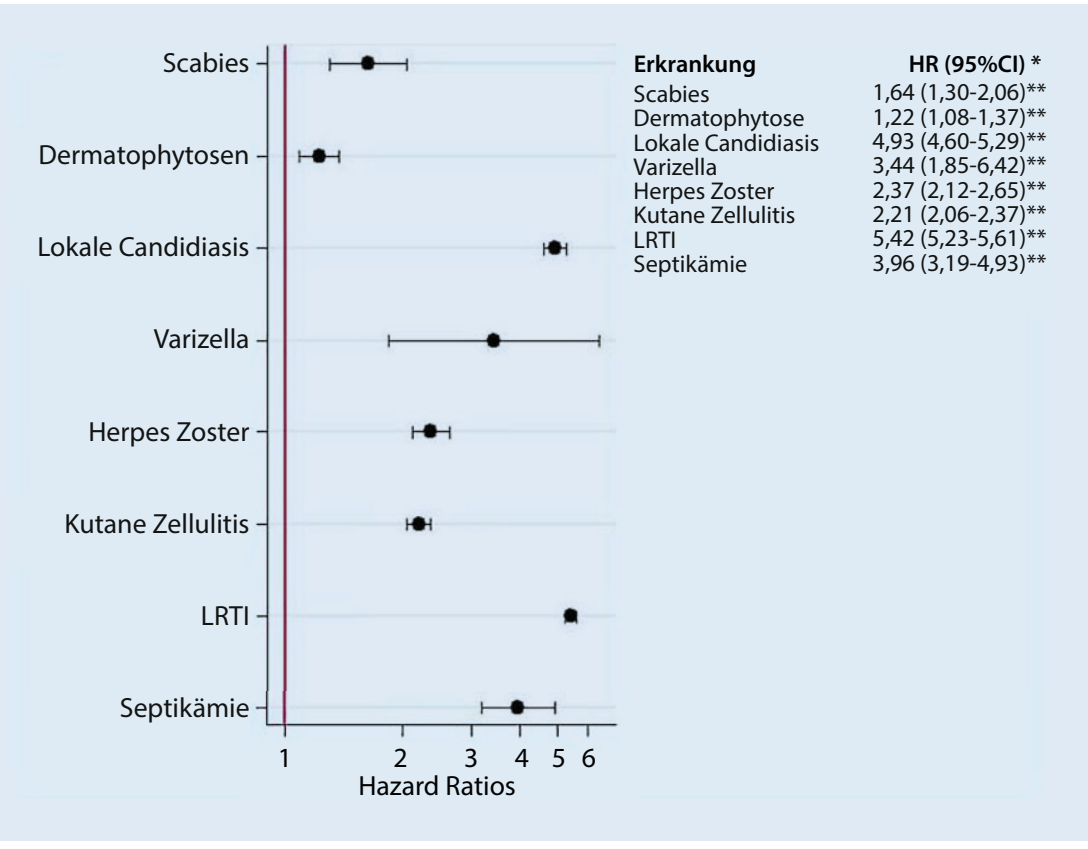

Abb. 17 ॥ Infektionsrisiko in der glukokortikoidexponierten Gruppe im Vergleich zu der nicht mit Glukokortikoiden behandelten Gruppe. LRTI "lower respiratory tract infection" (Infektion der unteren Atemwege). * angepasst für Geschlecht, Alter, Diabetes und Verwendung anderer Immunsuppressiva; ${ }^{* *} p<0,001$ für alle Infektionen außer Dermatophytose $(p=0,001)$ (Aus Fardet et al. [30], Open-AccessAbbildung)

Eine Erniedrigung der Lymphozytenzahl und der Quotient aus neutrophilen Granulozyten und Lymphozyten (Neutrophilen-Lymphozyten-Ratio (NLR)) sind als Prädiktor für einen schweren Verlauf einer COVID-19-Erkrankung identifiziert worden. Eine anhaltende und schwere Verminderung der peripheren Lymphozytenzahl ist i. Allg. mit einem höheren Risiko für die Entwicklung einer sekundären bakteriellen bzw. mykotischen Infektion verbunden [22].
Guan et al. fanden 2020 bei einer Untersuchung an 1099 Patienten heraus, dass 83,2\% der COVID-19-Patienten eine Lymphopenie aufwiesen. Je schwerer die Erkrankung ausgeprägt war, desto niedriger lag die Lymphozytenzahl. Schon bei Diagnosestellung kann eine Lymphozytopenie mit Werten $<1000 / \mu$ l vorliegen, dabei ist die Progredienz entscheidend für die Prognose [23].

In dem hier dargestellten Fallbericht der Superinfektion eines COVID-19-Patien- ten veranschaulicht 0 Abb. 16 den Verlauf der Lymphozytenzahlen des beschriebenen Patienten.

Es gibt Berichte aus der intensivmedizinischen Versorgung von COVID-19-Patienten über häufige unspezifische CRPErhöhungen, meist ohne Nachweis von infektiösen Erregern [24]. Allerdings zeigt die Auswertung vieler international durchgeführter Studien ein deutliches Biomarkerprofil in den Inflammationswerten während einer COVID-19-Pneumonie als Ausdruck des Zytokinsturms. Es scheint bei der Interpretation auf die Gesamtheit der Laborparameter anzukommen, nicht auf einen singulären Wert [25]. - Tab. 2 verdeutlicht diese Zusammenhänge.

Die Arbeit von Kaneko et al. aus 2020 zeigt darüber hinaus, dass SARS-CoV-2 zur Reduktion der B-Zellen und T-Helfer-Zellen führt [26]. Eine Veränderung des Immunsystems und eine daraus resultierende Immunschwäche tritt bei vielen schweren viralen Infektionen auf. So untersuchten Gu et al. 2005 die Auswirkung des "severe acute respiratory syndrome" (SARS) und fanden heraus, dass neben der pulmonalen Manifestation v.a. Zellen der Immunabwehr betroffen waren. Sie wiesen im Zytoplasma von Lymphozyten und Monozyten Virusbestandteile nach. Besonders die T-Helfer-Zellen waren betroffen [27]. Für Influenza (H5N1) wurde 2010 durch Gao ebenfalls ein Befall lymphatischer Organe beschrieben, ähnliches auch bei Ebola [28, 29].

Zum Zeitpunkt des beschriebenen Falls im Frühjahr 2020 gab es im Behandlungsalgorithmus der Corona-Erkrankung noch keine Empfehlung zur Gabe von Steroiden. Die beschriebene Superinfektion mit Leclercia adecarboxylata und Cryptococcus neoformans entstand unter einer Langzeitintensivtherapie ohne immunsupprimierende Medikamente. Dass die Möglichkeit einer Infektion unter immunsuppressiver Therapie mit Glukokortikoiden erhöht ist, konnten Fardet et al. 2016 in ihrer Studie nachweisen. Ausgewertet wurden hier Daten aus Großbritannien zwischen Januar 2000 und Dezember 2012. Dort war das Risiko einer Infektion unter Steroiden 2- bis 6-fach erhöht, im Vergleich zu einer Kontrollgruppe ohne Exposition mit Glukokortikoiden (- Abb. 17, [30]). 
Tab. 2 Darstellung der Biomarker aus verschiedenen Studien. (Aus Fraga-Silva et al. [25])

\begin{tabular}{|c|c|c|c|c|}
\hline & $\begin{array}{l}\text { Mild vs. } \\
\text { schwer }\end{array}$ & $\begin{array}{l}\text { Mild vs. } \\
\text { kritisch }\end{array}$ & $\begin{array}{l}\text { Schwer vs. } \\
\text { kritisch }\end{array}$ & $\begin{array}{l}\text { Überlebende vs. Nicht- } \\
\text { überlebende }\end{array}$ \\
\hline D-Dimer & $\Uparrow$ & $\Uparrow$ & - & $\Uparrow$ \\
\hline Serumamyloid A & $\Uparrow$ & $\Uparrow$ & - & $\Uparrow$ \\
\hline C-reaktives Protein & $\Uparrow$ & $\Uparrow$ & $\Uparrow$ & $\Uparrow$ \\
\hline Interleukin-6 & $\Uparrow$ & $\Uparrow$ & $\Uparrow$ & $\Uparrow$ \\
\hline Interleukin-10 & $\Uparrow$ & $\Uparrow$ & $\Uparrow$ & $\Uparrow$ \\
\hline Neutrophile & $\Uparrow$ & $\Uparrow$ & $\Uparrow$ & $\Uparrow$ \\
\hline $\begin{array}{l}\text { Neutrophile-Lympho- } \\
\text { zyten-Ratio }\end{array}$ & $\Uparrow$ & $\Uparrow$ & $\Uparrow$ & $\Uparrow$ \\
\hline Lymphozyten & $\Downarrow$ & $\Downarrow$ & - & $\Downarrow$ \\
\hline CD 4+-Zellen & $\Downarrow$ & $\Downarrow$ & - & $\Downarrow$ \\
\hline CD 8+-Zellen & $\Downarrow$ & $\Downarrow$ & - & $\Downarrow$ \\
\hline NK-Zellen & - & $\Downarrow$ & - & $\Downarrow$ \\
\hline \multicolumn{5}{|c|}{$\begin{array}{l}\text { CD } 4 \text { „Cluster-of-differentiation"-4-T-Helferzellen, CD } 8 \text { Cluster-of-differentiation-8-zytotoxische- } \\
\text { T Zellen, NK-Zellen natürliche Killerzellen } \\
\Uparrow \text { erhöht oder } \Downarrow \text { verringert in COVID-19-Patienten }\end{array}$} \\
\hline
\end{tabular}

Tab. 3 Multivariate Analyse von Prädiktoren, die unabhängig assoziiert sind mit Superinfektionen bei hospitalisierten Patienten mit COVID-19. (Nach Falcone et al. [41])

\begin{tabular}{|l|l|l|}
\hline Prädiktor & OR (95\%-KI) & $p$-Wert \\
\hline Intestinale Besiedlung durch CRE & $16,03(6,5-39,3)$ & $<0,001$ \\
\hline Invasive mechanische Beatmung & $5,58(2,4-13,1)$ & $<0,001$ \\
\hline IL-6 oder JAK-Inhibitoren & $5,09(2,2-11,8)$ & $<0,001$ \\
\hline CRP bei Aufnahme $>7 \mathrm{mg} / \mathrm{dl}$ & $3,59(1,7-7,7)$ & $\mathbf{0 , 0 0 1}$ \\
\hline Piperacillin/Tazobactam & $2,85(1,1-7,2)$ & $\mathbf{0 , 0 2 8}$ \\
\hline Fett gedruckte $\boldsymbol{p}$-Werte sind statistisch signifikant $(\boldsymbol{p}<0,05)$ & \\
\hline
\end{tabular}

Diese Befunde decken sich mit vielen verschiedenen vorherigen Untersuchungen zum Risiko einer Infektion unter einer Dauertherapie mit Glukokortikoiden [31-37].

In einer anderen Studie, durchgeführt im Zeitraum von Februar 2020 bis April 2020 an 78 COVID-19-Patienten in Italien, konnten Giacobbe et al. feststellen, dass die Gabe von Methylprednisolon ein unabhängiger Risikofaktor für die Entstehung von Blutstrominfektionen bei der intensivmedizinischen Therapie der CoronaErkrankung war [38]. Interessanterweise konnte im Infektionsgeschehen ein Vorteil von grampositiven Erregern im Gegensatz zu gramnegativen festgestellt werden, ähnlich wie dies bei der Infektion mit Influenza beobachtet wurde [39].

Eine weitere Untersuchung aus der ersten Coronawelle in Italien an der Universität Pisa zeigte an 69 COVID-19-Patienten mit insgesamt 109 Superinfektionen, dass neben der mechanischen Ventilation, die bei diesem Patientenkollektiv in der Regel sehr lange Zeiträume ausfüllt, die Veränderung des Mikrobioms des Darms einer der größten Risikofaktoren für eine Superinfektion darstellt. Neben Selektionsprozessen, die durch die COVID-19-Erkrankungen selbst innerhalb der mikrobiellen Flora des Darms passieren [40], scheint die Gabe von Piperacillin/Tazobactam im Sinne eines Breitspektrumantibiotikums durch die Selektion von Carbapenem-resistenten Enterokokken (CRE) im Darm einen enormen Einfluss auf das Risiko einer Superinfektion zu haben (-Tab. 3, [41]). Auch im vorliegenden Fall kam Piperacillin/Tazobactam, ebenso wie eine lange Beatmungsdauer zum Einsatz. CRE wurden allerdings nie nachgewiesen.

In einer Publikation von SalmantonGarcia et al. 2021 zeigte sich ein direkter Zusammenhang zwischen einer COVID-19assoziierten Aspergillose („COVID-19-associated pulmonary aspergillosis", CAPA) und der Einnahme von Kortikosteroiden während eines intensivmedizinischen Aufenthalts. Begleitende Risikofaktoren waren ein schlechter kardiovaskulärer Zustand, eine Niereninsuffizienz, Diabetes mellitus und Adipositas [42]. Interessanterweise deckt sich diese Beobachtung mit einer Studie aus 2018 zum Auftreten von Aspergillosen unter Influenzapneumonien, was einen direkten Zusammenhang einer Viruspneumonie mit dem Risiko einer Aspergilleninfektion vermuten lässt [43].

In Bezug auf den hier vorgestellten Fall muss man daher postulieren, dass die beschriebene seltene Superinfektion unter einer steroidfreien Therapie entstanden ist und somit die medikamentöse Immunsuppression sicherlich keinen entscheidenden Faktor gespielt hat. Allerdings muss Berücksichtigung finden, dass es hier andere einflussreiche Faktoren gab, so der Selektionsdruck durch die verschiedenen Antibiotika-Therapie-Regime und die grundsätzliche Immunmodulation durch die SARSCoV-2-Infektion [44].

\section{Fazit}

Infektionen mit SARS-CoV-2 sind sicher nicht regelhaft mit opportunistischen Infektionen vergesellschaftet, aber sie begünstigen diese offensichtlich durch den immunmodulatorischen Effekt der Erkrankung selbst oder iatrogen durch die medikamentöse Therapie, wie die Gabe von Steroiden oder die umfangreichen Therapien durch antibiotische Medikamente. Im dargestellten Fall waren die Erreger der Superinfektion Leclercia adecarboxylata und Cryptococcus neoformans, zwei nicht häufige Keime in Bezug auf behandlungspflichtige Pneumonien.

In der Literatur finden sich allerdings viele Falldarstellungen, bei denen diese Keime eben nicht nur bei immunsupprimierten oder immunkompromittierten $\mathrm{Pa}$ tienten auftraten, sondern auch junge gesunde Menschen betrafen. In den beschriebenen Fällen zeigten diese Keime in der Regel nur vereinzelte Antibiotikaresistenzen.

Es bleiben daher sicherlich die Fragen offen, inwieweit zum einen SARS-CoV-2 die Besiedelung mit seltenen Erregern grundsätzlich durch beschriebene immunmodulatorische Effekte begünstigt, und wie sich außerdem die aktuellen Therapieregime mit der Gabe von Steroiden, also Dexamethason und als Alternative Hydrocortison, 
so wie in der aktuellen Leitlinie empfohlen [45], auf diese opportunistischen Infektionen im Langzeitverlauf auswirken.

Unter diesen Aspekten lässt sich als Fazit die Empfehlung ableiten, im Verlauf der stationären COVID-19-Therapie kontinuierlich umfangreiche mikrobiologische Testungen vorzunehmen, um diese und andere opportunistischen Keime und Infektionen zu detektieren.

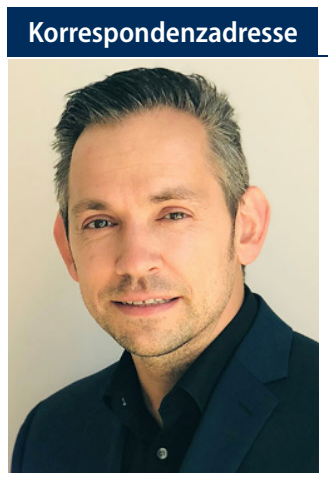

Dr. med. E. Gamon

Klinik für Anästhesiologie, Intensivmedizin und Notfallmedizin, Klinikum Links der Weser Bremen, Deutschland

e.gamon@mail.de

Dr. med. E. Gamon ist Oberarzt der Intensivmedizin in der Klinik für Anästhesiologie, Intensivmedizin und Notfallmedizin am Herzzentrum Links der Weser in Bremen. Er ist Facharzt für Anästhesiologie mit den Zusatzbezeichnungen "Anästhesiologische Intensivmedizin" und "Notfallmedizin".

\section{Einhaltung ethischer Richtlinien}

Interessenkonflikt. E. Gamon, D. Tammena, M. Wattenberg und T. Augenstein geben an, dass kein Interessenkonflikt besteht.

Für diesen Beitrag wurden von den Autoren keine Studien an Menschen oder Tieren durchgeführt. Für die aufgeführten Studien gelten die jeweils dort angegebenen ethischen Richtlinien. Für Bildmaterial oder anderweitige Angaben innerhalb des Manuskripts, über die Patienten zu identifizieren sind, liegt von ihnen und/oder ihren gesetzlichen Vertretern eine schriftliche Einwilligung vor.

\section{Literatur}

1. S3-Leitlinie Invasive Beatmung und Einsatz extrakorporaler Verfahren bei akuter respiratorischer Insuffizienz, AWMF Leitlinien-Register Nummer 001/021, Stand 4. Dez. 2017

2. Horby $P$ et al (2020) Dexamethason in hospitalized patients with Covid-19-preliminary report. N Engl J Med. https://doi.org/10.1056/ NEJMoa2021436
3. S3-Leitlinie Behandlung von erwachsenen Patienten mit ambulant erworbener Pneumonie und Prävention - Update 2016, AWMF LeitlinienRegister Nummer 020/020, Stand 31. Dez. 2015 (zurzeit in Revision)

4. S3-Leitlinie Epidemiologie, Diagnostik und Therapie erwachsener Patienten mit nosokomialer Pneumonie, AWMF Leitlinien-Register Nummer 020/013, Stand 11. Sept. 2017

5. Falagas M, Siempos I, Vardakas K (2008) Linezolid versus glycopeptide or $\beta$-lactam for treatment of Gram-positive bacterial infections: meta-analysis of randomised controlled trials. Lancet Infect Dis 8(1):53-66

6. Keivanidou A et al (2009) Ciprofloxacin induced acquired long QT syndrome in a patient under class III antiarrhythmic therapy. Cardiol J 16(2):172-174

7. Huang $C$ et al (2020) Clinical features of patients infected with 2019 novel coronavirus in Wuhan, China. Lancet 395(10223):497-506. https://doi. org/10.1016/S0140-6736(20)30183-5

8. Siddiqi HK, Mehra MR (2020) COVID-19 illness in native and immunosuppressed states: a clinical-therapeutic staging proposal. J Heart Lung Transplant 39(5):405-407. https://doi.org/ 10.1016/j.healun.2020.03.012

9. Wu Z, McGoogan JM (2020) Characteristics of and important lessons from the coronavirus disease 2019 (COVID-19) outbreak in china: summary of a report of 72314 cases from the chinese center for disease control and prevention. JAMA. https://doi. org/10.1001/jama.2020.2648

10. Leclerc $H$ (1962) Biochemical study of pigmented enterobacteriaceae. Ann Inst Pasteur 102:726-741

11. Chouddhary M et al (2018) Isolation and characterization of multidrug-resistant Leclercia species from animal clinical case. Lett Appl Microbiol 66(1):44-48

12. Hurley EH et al (2015) Leclercia adecarboxylata infection in an immunocompetent child. RI Med J 98(9):41-44

13. Jean SS et al (2016) Leclercia adecarboxylata bacteremia in a patient with long-term use of nonsteroidal antiinflammatory drugs. J Microbiol Immunol Infect 49(3):452-454 (Jun)

14. Merza N et al (2019) Leclercia adecarboxylata cholezystitis with septic shock in Immunocompeten patient. Case Rep Crit Care 2019:5057071. https:// doi.org/10.1155/2019/5057071

15. Eiland EH 3rd et al (2013) Pneumonia due to multidrug-resistant Leclercia adecarboxylata. Am J Health Syst Pharm 70(11):940-941 (Jun)

16. Prakash MR et al (2015) Hospital-acquired pneumonia due to Leclercia adecarboxylata in a neurosurgical centre. J Postgrad Med 61(2):123-125

17. Mokkapati A (2014) Leclercia Adecarboxylata isolation: case reports and review. J Clin Diagn Res 8(12):DD3-DD4

18. Keren $Y$ et al (2014) Is Leclercia adecarboxylata a new and unfamiliar marine pathogen? J Clin Microbiol 52(5):1775-1776

19. Lui G et al (2006) Cryptococcosis in apparently immunocompetent patients. QJM99(3):143-145

20. Cogliati M et al (2019) Genotypes and population genetics of cryptococcus neoformans and cryptococcus gattii species complexes in Europe and the mediterranean area. Fungal Genet Biol 128:16-29

21. Perfect RJ et al (2010) Clinical practice guidelines for the management of cryptococcal disease: 2010 update by the infectious disease Society of America. Clin InfDis 50(3):291-322

22. Yang AP et al (2020) The diagnostic and predictive role of NLR, d-NLR and PLR in COVID-19 patients.
Int Immunopharmacol 84:106504.https://doi.org/ 10.1016/j.intimp.2020.106504

23. Guan WJ et al (2020) Clinical characteristics of coronavirus disease 2019 in China. N Engl J Med 382(18):1708-1720. https://doi.org/10.1056/ NEJMoa2002032

24. Feldt T et al (2020) Welche Rolle spielt ein mögliches Hyperinflammationssyndrom bei einer schweren COVID-19-Infektion und können hieraus Konsequenzen für die Therapie gezogen werden? https://doi.org/10.25646/7037 (Robert-KochInstitut Fachgruppe COVRIIN, Stand: 27.07.2020)

25. Fraga-Silva et al (2021) COVID-19: integrating the complexity of systemic and pulmonary immunopathology to identify biomarkers for different outcomes. Front Immunol 11:599736. https://doi.org/10.3389/fimmu.2020.599736

26. Kaneko $\mathrm{N}$ et al (2020) Loss of Bcl-6-expressing $\mathrm{T}$ follicular helper cells and germinal centers in COVID-19. Cell 183(1):143-157

27. Gu J et al (2005) Multiple organ infection and the pathogenesis of SARS. J Exp Med 202(3):415-425

28. Martines RB etal (2015) Tissue and cellular tropism, pathology and pathogenesis of Ebola and Marburg viruses. J Pathol 235:153-174

29. Gao R et al (2010) A systematic molecular pathology study of a laboratory confirmed H5N1 human case. Plos One 5(10):e13315

30. Fardet L, Petersen I, Nazareth I (2016) Common infections in patients prescribed systemic Glucocorticoids in primary care: a population-based cohort study. PLoSMed 13(5):e1002024

31. Brassard P et al (2014) Oral corticosteroids and the risk of serious infections in patients with elderly-onset inflammatory bowel diseases. Am J Gastroenterol 109:1795-1802. https://doi.org/10. 1038/ajg.2014.313

32. Chang YS et al (2014) Tuberculosis infection in primary Sjögren's syndrome: a nationwide population-based study. Clin Rheumatol 33:377-383. https://doi.org/10.1007/s10067-013-2408-y

33. Fernàndez-Sabé $\mathrm{N}$ et al (2009) Risk factors, clinical features, and outcomes of listeriosis in solid-organ transplant recipients: a matched case-control study. Clin Infect Dis 49:1153-1159. https://doi. org/10.1086/605637

34. O'Donnell MR et al (1994) Prediction of systemic fungal infection in allogeneic marrow recipients: impact of amphotericin prophylaxis in high-risk patients. J Clin Oncol 12:827-834

35. Peleg AY et al (2007) Risk factors, clinical characteristics, and outcome of Nocardia infection in organ transplant recipients: a matched casecontrol study. Clin Infect Dis 44:1307-1314

36. Durand M, Thomas SL (2012) Incidence of infections in patients with giant cell arteritis: a cohort study. Arthritis Care Res 64:581-588

37. Durand M et al (2011) The influence of systemic glucocorticoid therapy upon the risk of nonserious infection in older patients with rheumatoid arthritis: a nested case-control study. Ann Rheum Dis 70:956-960. https://doi.org/10.1136/ard. 2010.144741

38. Giacobbe DR, Battaglini D, Ball L et al (2020) Bloodstream infections in critically ill patients with COVID-19. Eur J Clin Invest. https://doi.org/10. 1111/eci.13319

39. Metersky ML, Masterton RG, Lode H, File TM Jr., Babinchak T (2012) Epidemiology, microbiology, and treatment considerations for bacterial pneumonia complicating influenza. Int J Infect Dis 16(5):e321-e331

40. Zuo T, Liu Q, Zhang F et al (2020) Depicting SARSCoV-2 faecal viral activity in association with gut 
microbiota composition in patients with COVID-19. Gut. https://doi.org/10.1136/gutjnl-2020-322294

41. Falcone $M$ et al (2021) Predictors of hospitalacquired bacterial and fungal superinfections in COVID-19: a prospective observational study. J Antimicrob Chemother 76:1078-1084. https:// doi.org/10.1093/jac/dkaa530

42. Salmanton-García J et al (2021) COVID-19-associated pulmonary Aspergillosis, March-August 2020. Emerging Infect Dis 27(4):1077-1086. https://doi. org/10.3201/eid2704.204895

43. Dutch-Belgian Mycosis Study Group, Schauwvlieghe AFAD et al (2018) Invasive aspergillosis in patients admitted to the intensive care unit with severe influenza: a retrospective cohort study. Lancet Respir Med 6:782-792. https://doi.org/10. 1016/S2213-2600(18)30274-1

44. Schön MP et al (2020) COVID-19 und Immunregulation - von grundlegenden und translationalen Aspekten zu klinischen Implikationen. J Dtsch Dermatol Ges 18(8):795-809

45. S2k-Leitline Empfehlung zur stationären Therapie von Patienten mit COVID-19, AWMF LeitlinienRegister Nummer 113/001, Stand 23. Nov. 2020

46. https://commons.wikimedia.org/wiki/File: Escherichia_coli_electron_microscopy.jpg. Zugegriffen:28. Juli 2021

\section{Rare superinfection in a COVID-19 patient-A chronology}

After a resuscitation situation a SARS-CoV-2 sample from a 55-year-old man who had been in the hospital for elective ablation for atrial fibrillation was tested positive. The patient history revealed that there had been a previous confirmed contact with a COVID-19 positive patient. The patient developed the complete set of symptoms of COVID-19 pneumonia with extensive intensive care treatment. After about 2 weeks of treatment, weaning had to be stopped due to the deterioration of the severe septic condition of the patient and he showed microbiological evidence of a superinfection with Cryptococcus neoformans and later Leclercia adecarboxylata. The patient was treated successfully and survived the disease.

\section{Keywords}

Leclercia adecarboxylata · Cryptokokkus neoformans · Sepsis · ARDS · SARS-CoV-2 